03

\title{
Рефрактометрические параметры нелинейно-оптических молекулярных со-кристаллов на базе аминопиридинового ряда
}

\author{
(С) К.Е. Жевайкин, М.И. Фокина, И.Ю. Денисюк
}

Университет ИТМО,

197101 Санкт-Петербург, Россия

e-mail: kiraje92@yandex.ru

Поступила в редакцию 06.09.2017г.

\begin{abstract}
Проведены исследования показателей преломления новых нелинейно-оптических материалов на основе со-кристаллов 4-нитрофенола с аминопиридинами: 2-аминопиридин; 2,6-аминопиридин; 4-аминопиридин. Представлены значения показателей преломления исследуемых соединений: 2-aminopyridine-4-nitrophenol (2АР4N - метод оптической микроскопии: $n=1.72$, метод Аббе: $n=1.605$ ); 2,6-diaminopyridine-4-nitrophenol (2,6DAP4N - метод оптической микроскопии: $n=1.6$, метод Аббе: $n=1.589$ ); 4-aminopyridine-4nitrophenol (4AР4N - метод оптической микроскопии: $n=1.59$, метод Аббе: $n=1.591$ ).
\end{abstract}

DOI: $10.21883 /$ OS.2018.02.45529.201-17

\section{Введение}

Развитие нелинейно-оптических сред привело к созданию целого ряда молекулярных нелинейно-оптических кристаллов, из которых наиболее известны кристаллы MNA, POM и DAST, последний нашел широкое применение в терагерцовой технике [1].

Кристаллам DAST присущ ряд недостатков, главным из которых является нестабильность характеристик и быстрая деградация параметров в результате воздействия влаги и мощного лазерного излучения. По этой причине продолжается поиск других молекулярных кристаллов, обладающих нелинейно-оптическими свойствами.

Ранее нами были проведены исследования нелинейнооптических со-кристаллов аминопиридин-4-нитрофенола, которые показали достаточно высокие нелинейнооптические характеристики при отсутствии деградации как при действии лазерного излучения, так и влажности [2]. В настоящее время проводится исследование их терагерцовых параметров. При этом для применения нелинейно-оптических кристаллов как для удвоения частоты, так и в терагерцовой области важным параметром является показатель преломления как усредненный, так и величина показателя преломления по каждой кристаллической оси. В настоящей работе проведены такие исследования и измерены показатели преломления трех со-кристаллов 4-nitrophenol с тремя производными аминопиридина: 4-aminopyridine; 2,6-diaminopyridine; 2-aminopyridine.

\section{Используемые материалы и методы исследования}

Со-кристаллы аминопиридин-нитрофенол были приготовлены методом кристаллизации при медленном испа- рении растворителя. Метод и условия роста описаны нами ранее [2].

Обозначения кристаллов: 2-aminopyridine-4-nitrophenol - 2AP4N; 2,6-diaminopyridine-4-nitrophenol 2,6DAP4N; 4-aminopyridine-4-nitrophenol - 4AP4N.

Микрофотографирование кристаллов, а также исследования показателя преломления микроскопическим методом выполнялись на инструментальном микроскопе OlympusSTM6, измерение показателя преломления по методу Аббе выполнялось на рефрактометре ИРФ-454 Б2М. Иммерсионная жидкость при измерениях - альфа-бромнафталин.

Порядок проведения измерений показателя преломления по микроскопическому методу состоял в следующем: проводилась фокусировка на верхнюю поверхность кристалла и фиксировалось ее значение по оси $Z$, далее проводилась фокусировка на нижнюю поверхность кристалла. Далее определялась толщина образца также средствами инструментального микроскопа. Используя полученные значения верхней и нижней границ образца, определялась оптическая разность хода луча по формуле

$$
d-d_{1}=l,
$$

где $d-$ верхняя граница образца, $d_{1}-$ нижняя (кажущаяся) граница образца, $l$ - оптическая разность хода луча.

Опираясь на закон преломления и допустив рассмотрение лучей, близких к нормальному, нахождение показателя преломления осуществлялось по упрощенному соотношению

$$
n=\frac{d}{l},
$$

где $n-$ показатель преломления среды.

Для повышения точности получаемых результатов проводилась серия измерений по поверхности кристалла с определением среднего значения. 


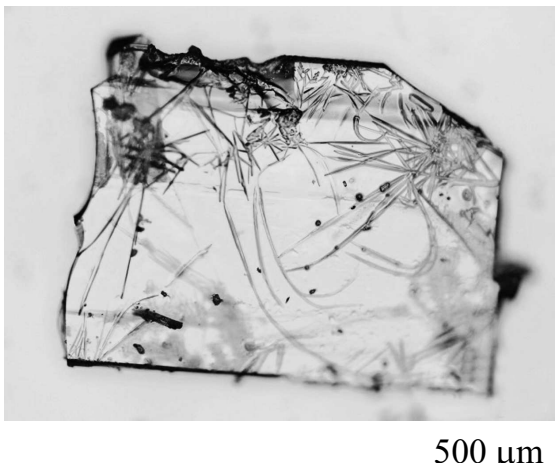

$b$

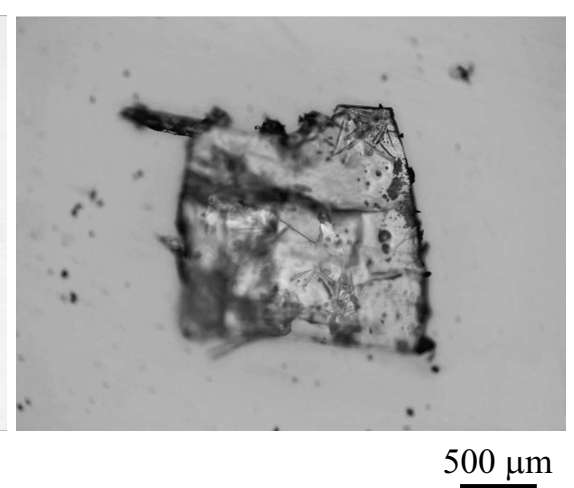

Рис. 1. Микрофотографии со-кристаллов, использованных в работе: (a) 2AP4N; (b) 2,6DAP4N; (c) 4AP4N.

Измерения проводились как с введенными скрещенными поляризаторами, так и без них. Для определения анизотропии показателя преломления исследуемые образцы фиксировались в центре предметного столика и пошагово измерялись через каждые $30^{\circ}$ до полного оборота предметного столика в $360^{\circ}$.

\section{Экспериментальные результаты и их обсуждение}

Исследуемые кристаллы приведены на рис. 1. При наблюдении в поляризованном свете были заметны дефекты типа двойникования. Эти дефекты могли приводить к неоднозначности результатов измерений анизотропии.

\section{Измерения показателя преломления по методу Аббе}

В качестве иммерсионной жидкости использовался альфа-бромнафталин. Измерения проводились по стандартной методике, длина волны света - 560 нм, неполяризованный свет. Были получены следующие значения показателей преломления кристаллов: $n(2 \mathrm{AP} 4 \mathrm{~N})=$ $=1.605 ; n(2,6 \mathrm{DAP} 4 \mathrm{~N})=1.589 ; n(4 \mathrm{AP} 4 \mathrm{~N})=1.591$.

Необходимо отметить, что в процессе измерений происходило медленное растворение кристаллов, что могло сказываться на точности полученных значений показателя преломления.

\section{Измерения показателя преломления по микроскопическому методу}

При измерении в неполяризованном свете микроскопическим методом были получены следующие значения показателей преломления кристаллов: $n(2 \mathrm{AP} 4 \mathrm{~N})=1.72$; $n(2,6 \mathrm{DAP} 4 \mathrm{~N})=1.6 ; n(4 \mathrm{AP} 4 \mathrm{~N})=1.59$.

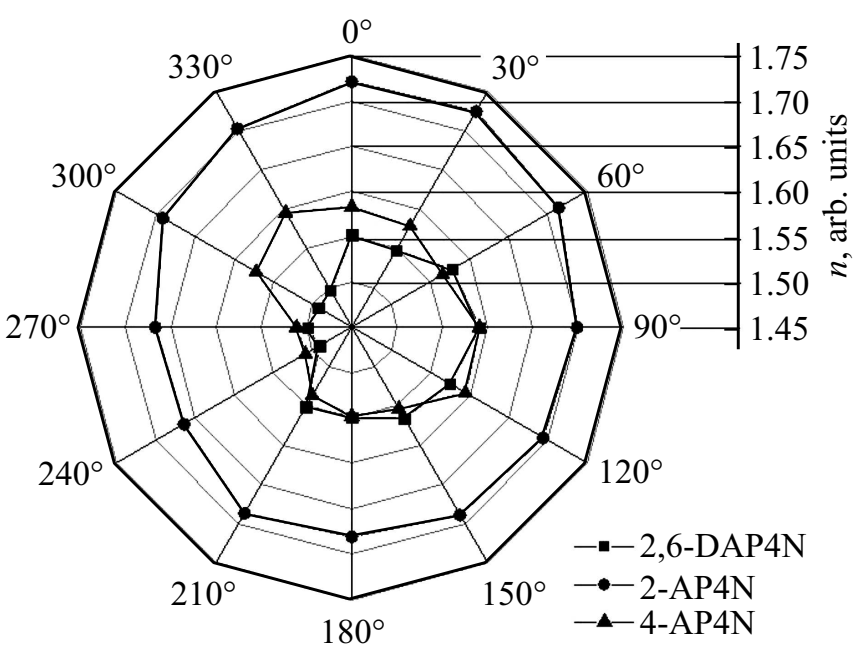

Рис. 2. Круговая диаграмма значений показателей преломления молекулярных со-кристаллов на основе производных аминопиридина с шагом поворота диска $30^{\circ}$.

Те же измерения проводились при введенных скрещенных поляризаторах микроскопа с целью определения анизотропии показателя преломления, связанной с различием показателя преломления по осям $X, Y, Z$ coкристалла. Результаты представлены на рис. 2.

Как следует из рис. 2, разность показателей преломления при повороте кристалла весьма значительна, что и должно иметь место для анизотропного двулучепреломляющего кристалла. В идеале диаграммы должны иметь форму эллипса, отклонение от эллиптической формы может быть объяснено неоднородностью кристалла либо сдвигом точки измерения по плоскости кристалла при его повороте. Наибольшая анизотропия показателя преломления наблюдается для кристалла 4AP4N: изменяясь от 1.5 до 1.6 при повороте кристалла на $90^{\circ}$. 


\section{Список литературы}

[1] Vijay R.J., Melikechi N., Kumar T.R., Jesudurai J.G.M., Sagayaraj P. // J. Crystal Growth. 2010. V. 312. P. 420.

[2] Pavlovetc I.M., Draguta S., Fokina M.I., Timofeeva T.V., Denisyuk I.Yu. // Opt. Commun. 2016. P. 64-68. 